\title{
FACILITY LOCATION OF ORGAN PROCUREMENT ORGANISATIONS IN INDIAN HEALTH CARE SUPPLY CHAIN MANAGEMENT
}

\author{
M. Rajmohan ${ }^{1 *}$, C. Theophilus ${ }^{1}$, M.R.Sumalatha ${ }^{2}$ \& S.Saravanakumar ${ }^{3}$
}

\section{ARTICLE INFO}

\section{Article details}

Submitted by authors 17 Feb 2016

Accepted for publication 14 Mar 2017

Available online 26 May 2017

\section{Contact details}

Corresponding author rajmohan@annauniv.edu

\section{Author affiliations}

1 Department of Industrial Engineering, Anna University, Chennai, India

2 Department of Information Technology, Anna University, Chennai, India

3 Department of Management Studies, Indian Institute of

Technology Madras, Chennai, India

DO

http://dx.doi.org/10.7166/28-1-1508
ABSTRACT

In health care supply chain management, particularly in the area of organ transplantation, organ procurement and the transplantation network play an important role. The organ procurement organisation (OPO) should coordinate so that organs are prepared and transported to the recipients when donors become available. The scarcity of organ supply leads to life-challenging issues for the organ recipient. In this research, the importance of the location of OPOs to coordinate with the transplant centres in India is considered, and a solution is provided by facilitating the identification of locations where organs can be procured and distributed to the nearest transplant location. The location of the distribution centres of organs are identified, based on the p-median model. This model minimises the weighted distance of the organ recipients. Initially, the demand or the population density of organ recipients with respect to particular location is recognised. Then, based on the p-median model, the location of OPOs is effectively identified. Experimental analysis proves that the proposed model performs well in facilitating the location of OPOs. The robustness of the proposed work is validated using a sensitivity analysis of the differences in the selection of OPOs when the estimated demand for organs varies.

\section{OPSOMMING}

Orgaanverkryging en die oorplantingsnetwerk speel 'n belangrike rol in die voorsieningkettingbestuur van gesondheidsorg. Die orgaan verkrygingsorganisasie moet koördineer dat organe voorberei en vervoer word na ontvangers soos wat skenkers beskikbaar word. Die skaarsheid gekoppel aan orgaanverskaffing lei tot lewensgevaarlike situasies vir die orgaanontvanger. Die belangrikheid van die ligging van orgaan verkrygingsorganisasies word oorweeg en 'n oplossing word verskaf deur die liggings waar organe verkry en versprei kan word na die naaste oorplantingsentrum te identifiseer. Die ligging van die verspreidingsentrums word deur middel van die $p$-mediaan model identifiseer. Die model minimeer die geweegde afstand tot by die orgaanontvangers. Eksperimentele analise bewys dat die voorgestelde model daarin slaag om die orgaan verkrygingsorganisasies se liggings te fasiliteer. Die robuustheid van die voorgestelde model is gevalideer deur middel van 'n sensitiwiteitsanalise van die verskille in die seleksie van orgaan verkrygingsorganisasies wanneer die geskatte vraag na organe wissel.

\subsection{Overview}

Human longevity has considerably improved as technology has improved especially in the past century due to the advancement of medical science [1]. The extent of organ failure that was quite 
common in the past due to ageing has now become very common due to chronic diseases and the use of certain medications [2]. There has been a drastic improvement in the field of organ transplantation since the first-ever transplant took place in 1954. This has been largely due to the discovery that the main reason behind graft rejection was blood group mismatch, and since then a permanent cure has been sought. Incidentally, the confidence of people to go for transplantation as a permanent treatment option has also increased [3]. A kidney transplant was the first ever organ transplantation in the world; and even in India, the number of kidney transplants far exceeds those of other organs. In fact, according to a population-based study in India, the incidence rate of crude and age-adjusted end-stage renal disease is estimated to be 151 and 232 per million population respectively. Another study states that, if the above numbers are validated and extended to other parts of the region, that would mean that between 220000 and 275000 new patients on average require kidney transplantsevery year. Though the number is alarming, only 3.25 patients per million get kidney transplants, thus increasing the gap between demand and supply. This is true not only for kidneys, but also for other transplanted organs. The increased gap between demand and supply is mainly because the lack of donor organs causes a steep increase in the waiting time of the patients, and because some people die while waiting for transplants [4]. The two main sources from whom organs are transplanted are living donors and cadaveric donors [5].

The demand for organs can be satisfied in one way by the cadaveric donors. Interestingly, less than two per cent of the donations are from cadaveric donors; all the remaining are from live donors; so the potential for harvesting organs from cadaveric donors is enormous [6]. Road traffic accidents have increased in recent years, reaching more than 110000 per year; and they are the major reason for the increase in cadaveric donors. According to the annual report of the Tamilnadu Network for Organ Sharing (TNOS) for the year 2013, of 15563 fatal road traffic accidents, 0.53 per centare converted to potential organ donors. If the same rate of conversion were observed throughout the nation, the number of potential organ donors would reach 800 donors.

The four states of Tamilnadu, Andhra Pradesh, Gujarat, and Maharashtra lead the country with a deceased organ donation rate of 0.3 per million population, compared with a mere 0.08 per million population of the national average. If the current deceased organ donation rate continues, it is possible that within two or three years the four southern states alone would generate a donation rate of one per million population. Provided the current national deceased organ donation rate of 0.08 per million population is pushed towards the goal of one per million population, it would satisfy the nation's need for all hearts, livers, and lungs and to an extent also satisfy the kidney shortage. Thus the great need for organs makes organ donation the most valuable gift. Unfortunately, the harvested organs are sometimes wasted because they reach the person who needs them only after 'cold ischaemia time', or because of the organ being rejected due to severe mismatch after transplantation. So this scarce resource must be treasured as a national resource, and every effort must be made to reduce wastage. Allocating these organs is not only a medical problem; it is also a social problem.

Health care supply chain management in industrial engineering supports analysis models to locate distribution centres. One of the models is the $p$-median, which has been efficiently applied to solve the road transportation system for Chiang Mai city [7]. The proposed model for OPOs (the p-median model) not only procures but also distributes organs, thereby catering to the needs of the national transplant centres by minimising time, mismatches, and distance.

\subsection{Organ procurement and transplantation}

The process of organ transplantation can be identified precisely by two key events: location and allocation. Essentially, three time-components are involved in the whole transplantation process: (1) the decision-making phase, where the correct matching is done and the available recipient is identified and decided on; (2) the explantation phase, where the organ is procured from the donor and transported to the recipient; and (3) the transplantation phase, where the explanted organ is transplanted into the recipient. Practically speaking, although a time factor is also involved in the recipient reaching the transplant centre, this can be considered as an internal element, as only available patients are considered for transplantation. The decision-making phase is determined by allocation policies, and the explantation is affected by the location decisions due to 'cold ischaemia time' (CIT). Once an organ becomes available, the organ matching process is carried out in concurrence with the convener of the cadaver transplant programme (CTP). After the matching, and if the patient is available for receiving, the organ is procured from the donor (known as explantation), and transported to the corresponding recipient hospital; and then the transplantation 
is carried out. The time involved in transporting the organ after explanting is critical, and is technically termed the 'cold ischaemia time' (CIT), where the organ is packed and protected in a cold perfusion solution and transported to the transplant centre before the transplant is performed. The quality of the organ is affected as this CIT increases and, based on this only the specific region which is closer for organ distribution must be determined. The overall decisions, in turn, affect the equity and efficiency issues that the country must balance for the smooth running of the transplant system.

The location has been a key issue in the sense that an OPO is located to cater to a particular region. This kind of operation was initiated as early as 1987 in the USA, where before the national system was formulated many OPOs co-existed, and each served its own area. These regional boundaries were maintained and continued when the national system was launched. A strategy of zonal configuration similar to that functioning in Tamilnadu is adapted and proposed for the OPO location identification in India.

\section{RELATED WORK}

In the existing systems, extensive research is carried out into various aspects of health care. A survey has initially been carried out on three levels, health care supply chain management, organ transplantation and networking, and facility location models to analyse the importance of facility location in organ transplantation networks.

\subsection{Health care supply chain management}

Hospitals currently hope to put cost-cutting measures in place for the services they provide in taking care of patients. Supply chain management in healthcare must facilitate the smooth running of services among suppliers, manufacturers, distributors, and customers.

The application of operations research in the area of healthcare facilities network design was exhaustively surveyed and presented by Papageorgiou [8] and Rais and Viana [9]. Mustaffa and Potter [10] developed a supply chain model for the healthcare industry. They focused on the distribution of medicines from a wholesaler to clinics, and addressed the issue of service levels at clinics. They also identified and built constructs to help to measure important coordination dimensions relevant to services. In the proposed system, a similar service model is described for the distribution of organs. Chakraborty, Bhattacharya and Dobrzykowski [11] considered the increasingly complex and interconnected nature of modern healthcare processes and their underlying information technology landscape. They conceptualised supply-chain collaboration and its related components to model healthcare processes that capture the outcome of collaboration. The current methodology should address and explore ways to include the communication channels used by the stakeholders throughout the process. In the proposed model, this concept is analysed and adapted for healthcare processes to optimise the time in the distribution of organs to the recipient of the organs.

In their study, Villa, Prenestini and Giusepi [12] provided an appraisal of healthcare supply chain management by underlining areas for improvement and determining obstacles to the application of logistics management practices for the flow of patients at three different levels: the hospital, the patient's journey within the hospital and the operating rooms, and the past and future plans of hospitals in developing their logistics management. A similar strategy is used in the proposed model to analyse organ procurement and the distribution of organs. Kolberg, Dahlgaard and Brehmer [13] proposed a holistic approach for prioritising lean initiatives in healthcare service operations. The work proposed here is also aimed at healthcare service operations, where the prioritisation of organ recipients based on emergency need is considered, and the distribution of organs is made effective using the p-median model.

In their work, Jain and Sakhuja [14] presented a case study on the structural investigation of a healthcare value chain, and discussed an important theoretical analysis for effective decisionmaking. They also highlighted the importance of how the roles of individual organisations vary, depending on their relative structural position and node level measures in the network. Their study is based theoretically on the Social Network Analysis (SNA) concept, but the method proposed here devises a mathematical model that effectively describes organ distribution; and in the future, the SNA method could be adapted to increase efficiency. 
Shretta, Johnson, Smith, Doumbia, Savigny, Anupindi and Yadav [15] addressed logistics and supply chain costs that reveal that there are several policies that lead to low costs. They estimated the country-level costs of the supply chain for a particular therapy and diagnostic tests in and around the regions of Benin and Kenya. This model is analysed and used in the system proposed here, to include more realistic operational scenarios, such as minimising the real time distance between the $\mathrm{OPO}$ and the relevant transplant centres. This could be an alternative for transportation costs with the help of the $\mathrm{p}$-median model.

lossifova and Goldstein [16] discussed the importance of healthcare supply chain data standards for providers, areas for improvement in provider operations, the potential advantages of standardising the healthcare data, and critical barriers to provider implementation. One of their motivations was to address the inefficiencies caused by the lack of a standard format for healthcare data. Their study showed the significance of a healthcare supply chain; the model proposed here also analyses the importance of healthcare supply chain issues in an organ transplantation network.

Law [17] showed that, in the competitive world in the field of medicine, there is a need to provide a high level of service, especially when there is a shortage in the local warehouse and a need to deliver in an emergency. Emergency ordering is not only costly but also dangerous for the patient. The author emphasised the need for a systematic study of the drugs logistics system in hospitals. This is considered in the work proposed here when the demand for organs is high, the services take medical urgency into account.

Nagurney, Masoumi and Yu [18] proposed a generalised network optimisation model that optimises the supply chain network of a lifesaving and perishable human blood bank. The current work understands the importance of a healthcare service. In the proposed model, the supply chain network is effectively designed for an organ transplantation network. Jabbarzadeh, Fahimnia and Seuring [19] developed a robust network design model for the supply chain of blood, especially during disasters. Their model assists in facility location and the allocation of blood banks for different post-disaster periods. A similar strategy is applied for the location of facilities for organ donation networking.

\subsection{Organ procurement and transplantation}

The organ procurement organisation delivers the organs to the transplant centres where the transplant will be performed. This process must occur quickly, as organs are only transplantable for a short period of time after they have been removed. To ensure that the organs are distributed effectively, researchers have provided different solutions and some of them are briefed in this section.

Sprockel and Agreda [20] developed a framework that allows efficient cooperation for human interaction, modelling the various stages of organ transplantation. In this work, the groupware application (using multi-agent systems) optimises the entire process, analysing the problems in the developing communication system for the organ transplant network. The communication system of Organ Procurement and Transplantation Network is strengthened, and the proposed model uses strategic decision-making to locate the organ procurement organisations with which all the transplant centres can be networked for optimal processing of the transplantation process.

Davis, Mehrotra, Friedewald, Daskin, Skaro, Abecassis and Ladner [21] discussed the development of a multiperiod linear optimisation model for sharing in the kidney transplantation system KSHARE for the United Network for Organ Sharing. The KSHARE that was developed can be used by the transplantation community ultimately to test alternative geographic organ allocation strategies, and to refine them iteratively to rectify the geographical disparities that may arise. The proposed model developed here removes geographical disparity by way of networking with the transplant centres all over India.

Campillo-Gimenez, Jouini, Bayat and Cuggia [22] used a medical decision-making method the modern case-based reasoning (CBR) technique. This method requires the help of a database of historical records to predict the patients' waiting list; but their work is limited, and does not consider the effective distribution of organs to the recipient during an emergency. In our work, a decision support system is developed to locate the transplant centres and to allocate organs effectively to that exact transplant centre. 
Penteado, Cohrs, Hummel, Erbs, Maciel, Ortolani, Roza, and Pisa [23] created a business process model in Brazil to demonstrate the kidney transplant process from initial placement on the waiting list to life post-transplant. The model helps to analyse the transplant process and its outcomes by validating it with the data from the six organisations and six different stages of the process. The model proposed in this study helps to locate the organ procurement organisation deterministically. A sensitivity analysis is executed at the same time to identify the changes in location.

Optimisation has been used for the allocation of organs where Righter [24], in the early days, used a stochastic sequential assignment problem to structure the allocation policies. David and Yaechiali [25] developed an infinite horizon model for allocation in the case of the simultaneous arrival of both patient and donor. Zenios, Chertow and Lawrence [26] studied the dynamic allocation of kidneys to candidates on the waiting list. Simulation studies have been done by many authors comparing different allocation policies and pre-transplant outcomes for specific organs [27-30].

\subsection{Facility location and p-median}

The facility location problems are analysed to locate a facility to reduce the time and cost in transferring an organ with respect to the healthcare supply chain between distributors and patients. The $p$-median problem locates $p$ facilities with the objective of optimising the average performance, such as minimising average distance and cost of transportation, average demand weighted distance, and total transit time. This model is also referred to as the 'minisum' problem and, in this work, it is applied to locate the OPOs in India.

Shariff, Moin and Omar [31] developed a capacitated maximal covering problem for the location allocation of healthcare facilities for a case study in one of the districts of Malaysia. The model was meant to determine the maximum coverage of existing facilities. In our approach, the coverage based on the cold ischaemia time is approximated for distance, and is solved by considering the problem as a p-median model.

Syam and Côté [32] proposed a location-allocation for the treatment of brain injuries. Their objective function was to minimise the total cost. They also considered three main factors: patient population density, centralisation of services, and retention of patients in relation to distance. In our proposed model, the patient population density for the separate hospitals, districts, and states is considered as an important factor in the objective.

An, Zeng, Zhang and Zhao [33] presented a robust $\mathrm{p}$-median model for a facility location problem dealing with an optimisation model that was subject to disruption. The two-stage robust optimisation scheme caters for the demand changes due to disruption and facility capacities. Our proposal uses the $\mathrm{p}$-median model to locate the organ procurement organisation, where an effective demand variation is also incorporated.

Kratica, Dugošija and Savić [34] addressed a multilevel uncapacitated facility location problem. A new mixed integer linear programming model with a profit maximisation objective and validity of the formulation was also explained. The solution was obtained using CPLEX and the Gurobi solver. Our proposed model involves a similar strategy to locate the organ procurement organisations in India, and CPLEX 12.5 was used to obtain the solution.

Kong, Shechter, Schaefer and Stahl [35] first initiated work on the location of transplant centres, especially to strike a balance between efficiency and equity. In the organ transplantation process in the USA, the entire state is divided into different transplant regions for effective coordination and networking. They worked with a regional configuration of the transplant centres in United States using a set partitioning algorithm. An important consideration in their study of the optimal configuration of these regions was to keep the 'local primacy' rule, which means that a primary objective of an OPO is to procure organs, and the OPO is connected to other transplant centres for the distribution of organs. Stahl, Kong, Shechter, Schaefer and Roberts [36] extended this with a detailed analysis to identify the optimal configuration of transplant regions in USA, based on the condition that the OPO is itself a procuring unit and is networked with other organ distribution units in the country. The order of priority for the allocation of organs is local, followed by regional, and then national. This strategy is applied in the work proposed here to locate transplantation centres in India, and the distribution of organs is based on the geographical locations of the transplantation centres. 
Bruni, Conforti, Sicilia and Trotta [37] developed a TRALOC model to locate and allocate organs, by considering the roles of procurement and distribution of OPOs distinctively in Italy. Belien, Boeck, Colpaert, Devesse and Bossche [38] presented a mixed integer linear programming model to optimise the location of the organ transplant centres to minimise the sum of time components involved from procuring the organ from the donor until the organ is transplanted to the recipient multiplied by certain weights. Recently, in a similar context, Zahiri, Tavakkoli-Moghaddam, Mohammadi and Jula [39] also developed a bi-objective model with the addition of including the waiting time in the queue for the transplantation procedure while keeping uncertainty in mind.

In summary, the work proposed here overcomes the limitations of the existing systems by considering the latitude and longitude positions of the transplant centres to identify the exact location of the OPOs in addition to co-ordination activities. The objective is met by considering several OPOs and forming regions based on their coverage constraint on cold ischaemia time rather than considering only one OPO another improvement on the existing studies. The location of the organ procurement and distribution organisation (OPDO) considered in this work makes it unique by minimising the distance between procurement and distribution centres.

\section{PROBLEM FORMULATION AS A P-MEDIAN FACILITY LOCATION MODEL}

The organ procurement organisation location is facilitated using the p-median model. The objective is to minimise the average weighted distance between the demand points and the closest facility. While the average distance of the covered demands is minimised, at the same time the average distance of the uncovered demands is maximised. The demand nodes have the capacity to function as a facility, thereby covering themselves and other nearby demand points in providing the nearest location. The p-median problem defined in the existing systems [40], [41] is modified to locate an organ procurement organisation and is explained below, starting with the notation. In the existing systems, p-median models are used to allocate schools and also ambulance locations in an emergency. In this research work, the p-median model is used to locate OPOs from among the available and approved transplant centres.

The mathematical notation and formulation of the problem is given below:

\section{Notation \\ Indices \\ $\mathrm{i}=$ set of demand transplant centres \\ $j=$ set of facility transplant centres or organ procurement organisations}

\section{Input parameters}

$D_{i j}=$ distance between demand transplant centre $i$ and facility transplant centre $j$

$h_{i}=$ weight of the demand transplant centre $i$

$\mathrm{P}=$ number of facility transplant centres to be located

\section{Decision variables}

$Y_{i j}=$ the demand transplant centre $i$ is covered by the facility transplant centre $j$

$X_{j}=$ facility transplant centre $j$

$$
\begin{gathered}
\text { Minimise } \sum_{i} \sum_{j} h_{i} D_{i j} Y_{i j} \\
\text { Subject to } \sum_{j} Y_{i j}=1 \quad \forall i \\
Y_{i j}-X_{j} \leq 0 \forall i, \forall j \\
\sum_{j} X_{j}=P
\end{gathered}
$$

The objective function (1) minimises the total weighted distance. Constraint (2) states that each demand node must be covered by at least one facility. Constraint (3) states that the demand nodes must be covered by only those facilities that are assigned. Constraint (4) states that there must be exactly P facilities that have to be located. Constraints (5) and (6) are integrality constraints. Organ transplantation may lead to organ wastage if a proper location is not identified. The distance 
between the location of the donor and the recipient hospital has to be as short as possible, and the exactly identified recipients have to be facilitated.

The present working model for organ allocation in Tamil Nadu considers dividing the state into three zones: North Zone, comprising Chennai, Kancheepuram, Vellore, and Thiruvallur; South Zone, comprising Madurai, Tirunelveli, and Nagercoil; and West Zone, comprising Coimbatore, Salem, and Tirupur. This kind of organisation into zones addresses the geographical disparity in organ-sharing, and ensures equity and efficiency in procuring and distributing the organs. In this work we have tried to identify the OPOs on the basis of the available and certified transplant centres for networking and coordinating in India as a whole, and so they are divided into states and districts as zonal functioning centres. The OPO itself is a transplant centre, and we have to identify the ' $n$ ' transplant centres that are to be networked to the OPOs and ready to be served, as provided by the p-median model. In India, the union ministry wanted to set up an autonomous national organ procurement and distribution organisation (NOPDO) headed at the centre, and coordinating and networking 10 state organ procurement and distribution organisations (SOPDO) under the new national organ transplant programme (NOTP). Under this programme the ten locations identified were Ahmedabad, Bangalore, Chandigarh, Chennai, Delhi, Hyderabad, Lucknow, Mumbai, Thiruvananthapuram, and West Bengal. The identified location for organ transplantation requires easy accessibility and facilities for the organ recipients. So the best way to select precise locations for the OPOs is provided by the proposed p-median model.

Table 1: States, districts and approved transplant centres

\begin{tabular}{|l|c|c|c|}
\hline States & Districts & Transplant centre districts & Transplant centres \\
\hline Andhra Pradesh & 13 & 1 & 2 \\
\hline Arunachal Pradesh & 16 & - & - \\
\hline Assam & 27 & - & - \\
\hline Bihar & 38 & - & - \\
\hline Chhattisgarh & 18 & - & - \\
\hline Goa & 2 & - & 10 \\
\hline Gujarat & 26 & 3 & 6 \\
\hline Haryana & 21 & 2 & - \\
\hline Himachal Pradesh & 12 & - & - \\
\hline Jammu and Kashmir & 22 & - & 25 \\
\hline Jharkhand & 24 & - & 18 \\
\hline Karnataka & 30 & 4 & - \\
\hline Kerala & 14 & 7 & 35 \\
\hline Madhya Pradesh & 50 & - & - \\
\hline Maharashtra & 35 & 6 & - \\
\hline Manipur & 9 & - & - \\
\hline Meghalaya & 7 & - & - \\
\hline Mizoram & 8 & - & - \\
\hline Nagaland & 11 & - & - \\
\hline Orissa & 30 & - & - \\
\hline Punjab & 20 & - & - \\
\hline Rajasthan & 33 & 2 & - \\
\hline Sikkim & 4 & - & - \\
\hline Tamil Nadu & 32 & 12 & - \\
\hline Telangana & 14 & - & - \\
\hline Tripura & 13 & - & - \\
\hline Uttar Pradesh & 19 & - & - \\
\hline Uttarakhand & & - & - \\
\hline West Bengal & 21 & - \\
\hline & & - & - \\
\hline
\end{tabular}

\subsection{Location and allocation of organ procurement organisations and networking of transplant centres in India}

The main objective of this research is to locate the organ procurement organisations in India optimally so that they can network and coordinate with the approved transplant centres. From the literature review it is clear that the p-median model could solve where to locate the OPOs, as the transplant centres should be within a reasonable distance and should cover the greatest number of persons needing a transplant, using the available facilities. These are taken care of by the coverage constraints of distance and demand (which is the population). Table 1 provides the details on the 
states in India, the number of districts in each state, and the number of transplant centres that have been approved.

The facility location using the p-median model was arrived at by identifying the places or transplant centres using latitude and longitude values, and the distance between the locations using 'the great circle' method. Table 2 below shows the location of a sample of 10 transplant centres in the region of Tamil Nadu.

Table 2: Latitude and longitude of a sample of ten approved kidney transplant hospitals in Tamil Nadu

\begin{tabular}{|c|l|c|c|}
\hline SI. No & \multicolumn{1}{|c|}{ Hospitals } & Latitude & Longitude \\
\hline 1 & Apollo First Med Hospitals & 13.0777 & 80.24595 \\
\hline 2 & Apollo Hospitals Enterprises Ltd & 13.06325 & 80.25148 \\
\hline 3 & Apollo Speciality Hospitals & 9.927883 & 78.14945 \\
\hline 4 & Ashwini Soundarya Nursing Home & 13.04118 & 80.25621 \\
\hline 5 & Assured Best Care Hospital Pvt Ltd & 10.83106 & 78.68441 \\
\hline 6 & Bharathi Rajaa Speciality Hospital and Research Centre & 13.04808 & 80.24506 \\
\hline 7 & Billroth Hospital, R.A Puram & 13.02894 & 80.25559 \\
\hline 8 & Billroth Hospital, Shenoy Nagar & 13.07581 & 80.22735 \\
\hline 9 & Chennai Kaliappa Hospital & 13.02744 & 80.25666 \\
\hline 10 & Chennai Meenakshi Multi Speciality Hosital Ltd & 13.03772 & 80.26149 \\
\hline
\end{tabular}

Table 3 provides the distance matrix for 10 transplant centres in Tamil Nadu. The distance between transplant centres was calculated using the formula for the great circle method.

Table 3: Distance matrix in kilometres between transplant hospitals in a sample of 10 hospitals in Tamil Nadu

\begin{tabular}{|c|c|c|c|c|c|c|c|c|c|c|}
\hline Hospitals & $T C 1$ & $T C 2$ & $T C 3$ & $T C 4$ & $T C 5$ & $T C 6$ & $T C 7$ & $T C 8$ & $T C 9$ & $T C 10$ \\
\hline$T C 1$ & 0 & 1.715 & 418.1 & 4.211 & 302.1 & 3.295 & 5.522 & 2.026 & 5.709 & 4.754 \\
\hline$T C 2$ & 1.715 & 0 & 417.1 & 2.508 & 301.1 & 1.824 & 3.841 & 2.963 & 4.022 & 3.039 \\
\hline$T C 3$ & 418.1 & 417.1 & 0 & 415.4 & 116.2 & 415.3 & 414.2 & 416.9 & 414.1 & 415.4 \\
\hline$T C 4$ & 4.211 & 2.508 & 415.4 & 0 & 299.4 & 1.431 & 1.363 & 4.96 & 1.529 & 0.689 \\
\hline$T C 5$ & 302.1 & 301.1 & 116.2 & 299.4 & 0 & 299.3 & 298.2 & 300.8 & 298.2 & 299.4 \\
\hline$T C 6$ & 3.295 & 1.824 & 415.3 & 1.431 & 299.3 & 0 & 2.415 & 3.631 & 2.617 & 2.121 \\
\hline$T C 7$ & 5.522 & 3.841 & 414.2 & 1.363 & 298.2 & 2.415 & 0 & 6.043 & 0.203 & 1.168 \\
\hline$T C 8$ & 2.026 & 2.963 & 416.9 & 4.96 & 300.8 & 3.631 & 6.043 & 0 & 6.246 & 5.623 \\
\hline$T C 9$ & 5.709 & 4.022 & 414.1 & 1.529 & 298.2 & 2.617 & 0.203 & 6.246 & 0 & 1.258 \\
\hline$T C 10$ & 4.754 & 3.039 & 415.4 & 0.689 & 299.4 & 2.121 & 1.168 & 5.623 & 1.258 & 0 \\
\hline
\end{tabular}

In order to normalise the allocation for all regions, the population density is considered instead of the population itself, to prevent the allocation from being skewed. The population density (taken as weight) for the state population and the district population were analysed separately. This model was solved, and the results obtained, using CPLEX software version 12.5.

\section{RESULTS AND DISCUSSION}

The solution is obtained by solving the p-median model using CPLEX version 12.5. Although there is much variation in the selection of hospitals, in the two cases where hospitals 94, 171, and 187 have much in common, neither they nor the other hospitals show much deviation in terms of distance. The patient waitlist for organs in Tamil Nadu is available on the website of the Tamil Nadu network for organ sharing (www.tnos.org). The waitlist of other states and districts are estimated based on 
the population density. The solution for 10 OPOs based on distance, and the demand for both state and district is shown separately in Tables 4 and 5 .

Table 4: Facilities selected as OPOs - State population density

\begin{tabular}{|c|c|l|}
\hline Sl.no & Node no. & \\
\hline 1 & 23 & Gospital Name \\
\hline 2 & 39 & Madurai Kidney Foundation, TN \\
\hline 3 & 49 & Sree Abirami Hospitals and Pvt. Ltd \\
\hline 4 & 64 & Gandhi Hospital, Hyderabad, Telangana \\
\hline 5 & 89 & Safdarjung Hospital, Delhi \\
\hline 6 & 94 & $\begin{array}{l}\text { Institute of Kidney Disease and Research Centre and Dr H.L. Trivedi Institute of } \\
\text { Transplantation Sciences, Ahmedabad, GJ }\end{array}$ \\
\hline 7 & 119 & Mallya Hospital, Bangalore, KN \\
\hline 8 & 137 & Lislie Hospital, Kochi, KL \\
\hline 9 & 171 & P.D. Hinduja Hospital, Mahim Mumbai, MH \\
\hline 10 & 187 & Apollo Hospital, Kolkata, WB \\
\hline
\end{tabular}

Table 5: Facilities selected as OPOs - District population density

\begin{tabular}{|c|c|l|}
\hline SI.no & Node no. & \\
\hline 1 & 4 & Ashwini Soundarya Nursing Home, Teynampet, TN \\
\hline 2 & 42 & MIOT Hospitals, Manappakkam, TN \\
\hline 3 & 68 & Lazarus Hospitals Limited, Hyderabad, Telangana \\
\hline 4 & 90 & Sir Ganga Ram Hospital, Delhi \\
\hline 5 & 94 & $\begin{array}{l}\text { Institute of Kidney Disease and Research Centre and Dr H.L. Trivedi Institute of } \\
\text { Transplantation Sciences, Ahmedabad, GJ }\end{array}$ \\
\hline $\mathbf{6}$ & 118 & Mallige Medical Centre, Bangalore, KN \\
\hline $\mathbf{7}$ & 128 & Amrita Institute of Medical Sciences and Research Centre, Kochi, KL \\
\hline $\mathbf{8}$ & 169 & Noble Hospital, Hadapsar, Pune, MH \\
\hline 10 & 171 & P.D. Hinduja Hospital, Mahim Mumbai, MH \\
\hline
\end{tabular}

A sensitivity analysis for variation in demand of the waitlist for the range of -20 per cent to +20 per centwas also done; itconfirmed selection of the same set of hospitals as organ procurement organisations. A variation in the p-median value to 5 and 15 and the selected OPOs and the associated transplant centres were obtained. Tables 6,7 , and 8 provide the solutions for $p$-medians $(p=5),(p=10)$, and $(p=15)$ respectively.

Table 6: Selected OPOs for $\mathrm{P}=5$ and associated transplant centres

\begin{tabular}{|c|c|l|c|}
\hline SI.no & Node no. & \multicolumn{1}{|c|}{ Hospital Name } & Transplant centres \\
\hline 1 & 33 & Kovai Medical Centre and Hospitals Ltd, TN & 68 \\
\hline 2 & 43 & Prasanth Multi Specialty Hospitals, Chennai, TN & 47 \\
\hline 3 & 76 & Fortis Flt. Lt. Rajan Dhall Hospital, Delhi & 30 \\
\hline 4 & 162 & Kohinoor Hospital, Kurla, MH & 45 \\
\hline 5 & 188 & Belle Vue Hospital, Kolkata, WB & 10 \\
\hline
\end{tabular}

Table 7: Selected OPOs for $\mathrm{P}=10$ and associated transplant centres

\begin{tabular}{|c|c|c|c|}
\hline SI.no & Node no. & Hospital name & Transplant centres \\
\hline 1 & 11 & Chennai Transplantation Centre, Mugappair, TN & 37 \\
\hline 2 & 20 & G. Kuppusamy Naidu Memorial Hospital, Coimbatore, TN & 24 \\
\hline 3 & 39 & Madurai Kidney Foundation, TN & 18 \\
\hline 4 & 64 & Gandhi Hospital, Hyderabad, Telangana & 10 \\
\hline 5 & 76 & Fortis Flt. Lt. Rajan Dhall Hospital, Delhi & 30 \\
\hline 6 & 94 & $\begin{array}{l}\text { Institute of Kidney Disease and Research Centre and Dr H.L. Trivedi Institute of } \\
\text { Transplantation Sciences, Ahmedabad, GJ }\end{array}$ & 10 \\
\hline 7 & 114 & K.R. Hospital, Bangalore, KN & 26 \\
\hline 8 & 164 & L.T.M.G Hospital, Mumbai, MH & 31 \\
\hline 9 & 167 & Meditrina Hospital, Nagpur, MH & 4 \\
\hline 10 & 188 & Belle Vue Hospital, Kolkata, WB & 10 \\
\hline
\end{tabular}


Table 8: Selected OPOs for $\mathrm{P}=15$ and associated transplant centres

\begin{tabular}{|c|c|c|c|}
\hline SI.no & Node no. & Hospital Name & Transplant centres \\
\hline 1 & 5 & Assured Best Care Hospital Pvt. Ltd, Trichy, TN & 7 \\
\hline 2 & 11 & Chennai Transplantation Centre, Mugappair, TN & 37 \\
\hline 3 & 20 & G. Kuppusamy Naidu Memorial Hospital, Coimbatore, TN & 13 \\
\hline 4 & 32 & Kidney Care Centre, Tirunelveli, TN & 8 \\
\hline 5 & 38 & $\begin{array}{l}\text { Madurai Kidney Centre and Transplantation Research Institute, } \\
\text { TN }\end{array}$ & 5 \\
\hline 6 & 62 & Care Hospitals, Vizag, AP & 2 \\
\hline 7 & 68 & Lazarus Hospitals Limited, Hyderabad, Telangana & 8 \\
\hline 8 & 89 & Safdarjung Hospital, Delhi & 24 \\
\hline 9 & 94 & $\begin{array}{l}\text { Institute of Kidney Disease and Research Centre and Dr H.L. } \\
\text { Trivedi Institute of Transplantation Sciences, Ahmedabad, GJ }\end{array}$ & 10 \\
\hline 10 & 114 & K.R. Hospital, Bangalore, KN & 25 \\
\hline 11 & 137 & Lislie Hospital, Kochi, KL & 10 \\
\hline 12 & 164 & L.T.M.G Hospital, Mumbai, MH & 31 \\
\hline 13 & 167 & Meditrina Hospital, Nagpur, MH & 4 \\
\hline 14 & 181 & Apex Hospitals, Jaipur, RJ & 6 \\
\hline 15 & 188 & Belle Vue Hospital, Kolkata, WB & 10 \\
\hline
\end{tabular}

The average number of associated transplant centres for $p$-median $(p=5)$ to the OPOs is 40 , for $p$ median $(p=10)$ it is 20 , and for $p$-median $(p=15)$ it is 13.33 . The optimal number of facilities, fixed at $p=10$, proves to be best. This is because, in the case of $p=5$, the number of transplant centres to be handled by each OPO increases; and in the case of $p=15$, the standard deviation is 10.33 , with one OPO having to handle only two transplant centres; and this indicates that even though the number of facilities are increased the number of transplant centres are not equally shared, and some OPOs would have to serve the same transplant centres in order to minimise the weighted distance.

The experimental observation reveals that when the value of $p$ is increased,one OPO is replaced by two other OPOs, but they serve the sametransplant centres, because the model tries tominimise the weighted distance between the OPO and the transplant centres. Tables 9,10, and 11 provide a comparison of the solutions for OPOs obtained from states (case 1), districts (case 2), and hospital population densities (case 3 ) respectively, with the proposed locations that the union ministry has suggested for consideration. From the results obtained for the $p$-median model of 10 facilities, the best and the nearest optimal transplant centre to the places that are currently proposed by the union ministry is compared and selected against all necessary criteria. Chandigarh, Lucknow, and Trivandrum are the three places proposed by the union ministry that are not in line with the options proposed by the model. Instead of locating the OPO in Trivandrum, the model identifies locationsin Kochi and Coimbatore, as they are closer to each other, compared with Trivandrum. The number of OPOs selected in Tamilnadu is three (Chennai, Coimbatore, or Madurai) in cases 1 and 3, and two OPOs (Chennai itself) in case 2. Similarly, the OPOs selected in Maharashtra are Mumbai in case 1, Mumbai and Pune in case 2, and Mumbai and Nagpur in case 3. More OPOs in these two states are identified because a large number of transplant centres are located in these states.

Even though communication plays a significant role in coordination and networking for organ distribution, the distance between the source and the destination should be given equal importance, as it involves the logistics of the organ. So, based on the optimal locations suggested for the different cases in the model, there is provision to choose the best location incorporating the distance criteria along with other factors such as infrastructure, population, disease population, donations, and giving preference to Government hospitals. Indeed, there is definitely scope to consider it as a multicriteria facility location problem to obtain practical and better solutions for the future. In this location model,10 OPOs are selected from a larger number of available transplant centres (200), aiming tominimise the weighted demandthe population density and the population proportion of the patient waitlist as separate cases. 
Table 9: Comparison of the solution obtained for state population density data with the proposed locations of OPOs

\begin{tabular}{|c|l|l|l|l|l|}
\hline \multirow{2}{*}{ SI.no } & Government policy & \multicolumn{3}{|c|}{ State population density } \\
\cline { 2 - 6 } & \multicolumn{1}{|c|}{ City } & State & \multicolumn{1}{|c|}{ Hospital } & City & State \\
\hline $\mathbf{1}$ & Ahmedabad & GJ & $\begin{array}{l}\text { Institute of Kidney Disease and } \\
\text { Research Centre }\end{array}$ & Ahmedabad & GJ \\
\hline $\mathbf{2}$ & Bangalore & KN & Mallya Hospital & Bangalore & KN \\
\hline $\mathbf{3}$ & Chandigarh & Chn & KMC Hospital & Chennai & TN \\
\hline $\mathbf{4}$ & Chennai & TN & Madurai Kidney foundation & Madurai & TN \\
\hline $\mathbf{5}$ & Delhi & Del & Sree Abirami Hospitals & Coimbatore & TN \\
\hline $\mathbf{6}$ & Hyderabad & Tel & Safdarjung Hospital & Delhi & Del \\
\hline $\mathbf{7}$ & Lucknow & UP & Gandhi Hospital & Hyderabad & Tel \\
\hline $\mathbf{8}$ & Mumbai & MH & P.D.Hinduja Hospital & Mumbai & MH \\
\hline $\mathbf{9}$ & Trivandrum & KL & Lislie Hospital & Kochi & KL \\
\hline $\mathbf{1 0}$ & West Bengal & WB & Apollo Hospital & Kolkata & WB \\
\hline
\end{tabular}

Table 10: Comparison of the solution obtained for district population density data with the proposed location of OPOs

\begin{tabular}{|c|l|l|l|l|l|}
\hline \multirow{2}{*}{ SI.no } & \multicolumn{1}{|c|}{ Government policy } & \multicolumn{3}{|c|}{ District population density } \\
\cline { 2 - 6 } & \multicolumn{1}{|c|}{ City } & State & \multicolumn{1}{|c|}{ Hospital } & State \\
\hline $\mathbf{1}$ & Ahmedabad & GJ & $\begin{array}{l}\text { Institute of Kidney Disease and } \\
\text { Research Centre }\end{array}$ & Ahmedabad & GJ \\
\hline $\mathbf{2}$ & Bangalore & KN & Mallige Medical Centre & Bangalore & KN \\
\hline $\mathbf{3}$ & Chandigarh & Chn & Aswini Soundarya Nursing Home & Chennai & TN \\
\hline $\mathbf{4}$ & Chennai & TN & MlOT Hospital & Chennai & TN \\
\hline $\mathbf{5}$ & Delhi & Del & Sir Ganga Ram Hospital & Delhi & Del \\
\hline $\mathbf{6}$ & Hyderabad & Tel & Lazarus Hospitals & Hyderabad & Tel \\
\hline $\mathbf{7}$ & Lucknow & UP & P.D.Hinduja Hospital & Mumbai & MH \\
\hline $\mathbf{8}$ & Mumbai & MH & Noble Hospital & Pune & MH \\
\hline $\mathbf{9}$ & Trivandrum & KL & $\begin{array}{l}\text { Amrita Institute of Medical Sciences } \\
\text { and Research Centre }\end{array}$ & Kochi & KL \\
\hline $\mathbf{1 0}$ & West Bengal & WB & Apollo Hospital & Kolkata & WB \\
\hline
\end{tabular}

Table 11: Comparison of the solution obtained for hospital population density data with the proposed location of OPOs

\begin{tabular}{|c|l|l|l|l|l|}
\hline \multirow{2}{*}{ Sl.no } & Government policy & \multicolumn{3}{|c|}{ Hospital population density } \\
\cline { 2 - 6 } & \multicolumn{1}{|c|}{ City } & State & \multicolumn{1}{|c|}{ Hospital } & \multicolumn{1}{c|}{ City } & State \\
\hline $\mathbf{1}$ & Ahmedabad & GJ & $\begin{array}{l}\text { Institute of Kidney Disease and } \\
\text { Research Centre }\end{array}$ & Ahmedabad & GJ \\
\hline $\mathbf{2}$ & Bangalore & KN & K.R.Hospital & Bangalore & KN \\
\hline $\mathbf{3}$ & Chandigarh & Chn & Chennai Transplantation Centre & Chennai & TN \\
\hline $\mathbf{4}$ & Chennai & TN & G.Kuppusamy Naidu Memorial Hospital & Coimbatore & TN \\
\hline $\mathbf{5}$ & Delhi & Del & Madurai Kidney Foundation & Madurai & TN \\
\hline $\mathbf{6}$ & Hyderabad & Tel & Fortis Flt.Lt. Rajan Dhall Hospital & Delhi & Del \\
\hline $\mathbf{7}$ & Lucknow & UP & Gandhi Hospital & Hyderabad & Tel \\
\hline $\mathbf{8}$ & Mumbai & MH & L.T.M.G. Hospital & Mumbai & MH \\
\hline $\mathbf{9}$ & Trivandrum & KL & Meditrina Hospital & Nagpur & MH \\
\hline $\mathbf{1 0}$ & West Bengal & WB & Belle Vue Hospital & Kolkata & WB \\
\hline
\end{tabular}

The model locates the transplant centres to function as OPOs, based on the shortest distance between the other transplant centres, in order to satisfy demand. In future, the location can be analysed and modeled dynamically with the help of a geographical information system (GIS) and the existing traffic information at any particular moment. This can reveal several different ways to 
assess the time of travel and thus to select the best OPOs. It can also be extended by relaxing other assumptions such as the length of road, type of road, gradient of the road, slowing down due to urban areas, congestion effects, one-way roads, and speed restrictions in particular areas, to make it more ideal for practical situations.

The current policies for organsharing and networking in Tamilnaduespecially for kidneys determine the order in which organs are distributed: first to the transplant centre in which the organ is recovered, then to the nearby zonal transplant centre waitlist, then to Government hospitals, and only then to private hospitals. Finally, if no match is found in any of them, the organ goes to the Government transplant centre in a nearby state, followed by any private transplant centres; otherwise it is given to a foreign national. If the organs are retrieved in a non-transplant centre, then they are allotted first to the combined waitlist of Government and private transplant centres within the state, followed by the combined list of Government and private transplant centres outside the state, and then, as usual, to a foreign national if no match is found in either case. In our case of national organ-sharing, instead of zones, the districts and states are studied,with the obtained results locating the OPOs. The proposed facility location model provides solutions for locating the OPOs and their associated transplant centres. The OPO to which the second organ (or the shared organ) has to be distributed, and the people to whom the organ has to be allocated, is the subject of ongoing research.

\section{CONCLUSION AND FUTURE WORK}

This research work helps in facilitatingidentification of locations of OPOs in organ transplantation network based on the p-median model. This model facilitates OPO location where organs are procured and distributed to centres. The facility location method using the p-median offers a practical approach to an application related to health care supply chain management and it acts as a decision support mechanism for the decision makers in determining the location of OPOs.

The future scope of this research is to group the districts and states, based on other factors such as number of donations, number of waitlisted patients, transplant centers in the area etc., in order to optimise organ sharing and to limit the disadvantages involved in organ sharing.

\section{REFERENCES}

[1] Oeppen, J. \& Vaupel, J.W. 2002. Broken limits to life expectancy, Science, 296(5570), pp. 1029-1031.

[2] Perneger, T.V., Whelton, P.K. \& Klag, M.J. 1994. Risk of kidney failure associated with the use of acetaminophen, aspirin, and nonsteroidal antinflammatory drugs, The New England Journal of Medicine, 331, pp. 1675-1679.

[3] Frohn, C., Fricke, L., Puchta, J.C. \& Kirchner, H. 2001. The effect of HLA-C matching on acute renal transplant rejection, Nephrology, dialysis, transplantation: Official publication of the European Dialysis and Transplant Association - European Renal Association, 16 (2), pp. 355-60.

[4] Veerappan, I., Neelakantan, N., Tamilarasi, V. \& John, G.T. 2011. Medical and non-medical factors that affect voluntary living-related kidney donation: A single-center study, Indian Journal of Nephrology, 21, pp. 14-20.

[5] Gregory, S.I. \& Glen, W.P. 2009. Donor selection and management, Current opinion in organ transplantation, 14(5), pp. 471-476.

[6] Sakhuja. V. \& Sud. K. 2003. End-stage renal disease in India and Pakistan: Burden of disease and management issues, Kidney International Supplements, 83, pp. 115-8.

[7] Sittipong, D. \& Chulin, L. 2014.Applied p-median and p-center algorithms for facility location problems, Expert Systems with Applications, 41(8), pp. 3596-3604.

[8] Papageorgiou, J.C. 1978. Some operations research applications to problems of health care systems (a survey), International Journal of Bio-medical Computing, 9, pp. 101-114.

[9] Rais, A. \& Viana, A. 2010. Operations research in healthcare: A survey, International Transactions in Operations Research, 18, pp. 1-31.

[10] Mustaffa, N.H. \&Potter, A. 2009. Healthcare supply chain management in Malaysia: A case study, Supply Chain Management: An International Journal, 14(3), pp. 234-243.

[11] Chakraborty, S., Bhattacharya, S. \& Dobrzykowski, D.D. 2014. Impact of supply chain collaboration on value co-creation and firm performance: A healthcare service sector perspective, Procedia Economics and Finance, 11, pp. 676-694.

[12] Villa, S., Prenestini, A. \&Giusepi, I. 2014. A framework to analyze hospital-wide patient flow logistics: Evidence from an Italian comparative study, Health Policy, 115(2-3), pp. 196-205.

[13] Kollberg, B., Dahlgaard, J.J. \& Brehmer, P. 2007. Measuring lean initiatives in health care services: Issues and findings, International Journal of Productivity and Performance Management, 56 (1), pp. 7-24. 
[14] Jain, V. \& Sakhuja, S. 2014. Structural investigation of a healthcare value chain: A social network analysis approach, IEEE International Conference on Industrial Engineering and Engineering Management, pp. 179183.

[15] Shretta, R., Johnson, B., Smith, L., Doumbia, S., Savigny, D., Anupindi, R. \& Yadav, P. 2015. Costing the supply chain for delivery of ACT and RDTs in the public sector in Benin and Kenya, Malaria Journal, 14(57), pp. 1-14.

[16] lossifova, A.R. \& Goldstein, S.M. 2013. Impact of standards adoption on healthcare transaction performance: The case of HIPAA, International Journal of Production Economics, 141(1), pp. 277-285.

[17] Law, K.M.Y. 2016. How schedule issues affect drug logistics operations: An empirical study in hospitals in China, Industrial Management \& Data Systems, 116(3), pp. 369-387.

[18] Nagurney, A., Masoumi, A.H. \& Yu, M. 2012. Supply chain network operations management of a blood banking system with cost and risk minimization, Computational Management Science, 9(2), pp. $205-231$.

[19] Jabbarzadeh, A., Fahimnia, B. \& Seuring, S. 2014. Dynamic supply chain network design for the supply of blood in disasters: A robust model with real world application, Transportation Research Part E: Logistics and Transportation Review, 70, pp. 225-244.

[20] Sprockel, J. \& Agreda, A. 2014. Technology oriented collaboration through multi-agent systems in operation of a group of transplantation, 9th Computing Colombian Conference (9CCC), pp. 21-28.

[21] Davis, A.E., Mehrotra, S., Friedewald, J.J., Daskin, M.S., Skaro, A.I., Abecassis, M.M. \& Ladner, D.P. 2015. Improving geographic equity in kidney transplantation using alternative kidney sharing and optimization modeling, Medical Decision Making, 35(6), pp. 797-807.

[22] Campillo-Gimenez, B., Jouini, W., Bayat, S. \& Cuggia, M. 2013. Improving case-based reasoning systems by combining k-nearest neighbour algorithm with logistic regression in the prediction of patients' registration on the renal transplant waiting list, PLoS One, 8(9), pp. 1-10.

[23] Penteado, A.P., Cohrs, F.M., Hummel, A.D., Erbs, J., Maciel, R.F., Ortolani, C.L.F., Roza, B.A. \& Pisa, I.T. 2015. Kidney transplantation process in Brazil represented in business process modeling notation, Transplantation Proceedings,47(4), pp. 963-966.

[24] Righter, R. 1989. A resource allocation problem in a random environment, Operations Research, 37(2), pp. 329-338.

[25] David, I. \& Yachiali, U. 1985. A time-dependent stopping problem with application to live organ transplants, Operations Research, 33(3), pp. 491-504.

[26] Zenios, S.A., Chertow, G.M. \& Lawrence, M.W. 2000. Dynamic allocation of kidneys to candidates on the transplant waiting list, Operations Research, 48 (4), pp. 549-569.

[27] Davis, A., Friedewald, J., Mehrotra, S. \& Ladner, D.P. 2013. Characteristics of a simulation model of the National Kidney Transplantation System, Winter Simulations Conference (WSC), pp. 2320-2329.

[28] Wilbert, B., Smits J.M.A., Deng, M.C., Hummel, M., Schoendube, F., Scheld, H., Persijn, G. \& Laufer, G. 2003. The heart allocation simulation model: A tool for comparison of transplantation allocation policies, Transplantation, 6(10), pp. 1492-1497.

[29] Wolfe, R.A., McCullough, K.P. \& Leichtman, A.B. 2009. Predictability of survival models for waiting list and transplant patients: Calculating LYFT, American Journal of Transplantation, 9, pp. 1523-1527.

[30] Thompson, D., Waisanen, L., Wolfe, R., Merion, R.M., Mccullough, K. \& Rodgers, A. 2004. Simulating the allocation of organs for transplantation, Health Care Management Science, 7, pp. 331-338.

[31] Shariff, S., Moin, N.H. \& Omar, M. 2012. Location allocation modeling for healthcare facility planning in Malaysia, Computers and Industrial Engineering, 62, pp. 1000-1010.

[32] Syam, S.S. \& Côté, M.J. 2010. A location-allocation model for service providers with application to notfor-profit health care organizations, Omega, 38, pp. 157-166.

[33] An, Y., Zeng, B., Zhang, Y. \& Zhao, L. 2014. Reliable p-median facility location problem: Two-stage robust models and algorithms, Transportation Research Part B: Methodological, 64, pp. 54-72.

[34] Kratica, J., Dugošija, D. \& Savić, A. 2014. A new mixed integer linear programming model for the mult level uncapacitated facility location problem, Applied Mathematical Modelling, 38(7-8), pp. 2118-2129.

[35] Kong, N., Shechter, S., Schaefer, A. \& Stahl, J.E. 2002. Organ transplantation regions: The need for optimization, IIE 2002 IERC, Orlando, Florida, May 2002.

[36] Stahl, J.E., Kong, N., Shechter, S.M., Schaefer, A.J. \& Roberts, M.S. 2005. A methodological framework for optimally reorganizing liver transplant regions, Medical Decision Making, 25(1), pp. 35-46.

[37] Bruni, M.E., Conforti, D., Sicilia, N. \& Trotta, S. 2006. A new organ transplantation location-allocation policy: A case study of Italy, Health Care Management Science, 9(2), pp. 125-142.

[38] Belien, J., Boeck, L.D., Colpaert, J., Devesse, S. \& Bossche, F.V. 2013. Optimizing the facility location design of organ transplant centers, Decision Support Systems, 54(4), pp. 1568-1579.

[39] Zahiri, B., Tavakkoli-Moghaddam, R., Mohammadi, M. \& Jula, P. 2014. Multi-objective design of an organ transplant network under uncertainty, Transportation Research Part E, 72, pp. 101-124.

[40] Hakimi S.L. 1964. Optimum locations of switching centres and the absolute centres and medians of a graph, Operations Research, 12(3), pp. 450-459.

[41] Balinski M.L. 1965. Integer programming: Methods, uses and computation, Management Science, 12, pp. 253-313. 